Revista do Programa de Pós-Graduação em Mídia e Cotidiano

Artigo Seção Dossiê Mídia e Cidade

Número 6. Volume 6 /Julho 2015

(C) 2015 by UFF

\title{
REDES SOCIAIS DIGITAIS NA ESFERA PÚBLICA POLÍTICA EXERCÍCIOS DE CIDADANIA
}

\section{DIGITAL SOCIAL NETWORKS IN THE POLITICAL PUBLIC SPHERE:}

\author{
Exercises of Citizenship
}

Resumo: As recentes manifestações ocorridas no Brasil e no mundo inspiram o estudo de variados temas e principalmente fazem refletir sobre o poder da ação a partir do uso da linguagem. Procura-se neste artigo verificar a potencialidade do uso político da linguagem no âmbito das redes sociais na internet à luz do conceito de esfera pública política e tendo como pano de fundo as manifestações ocorridas no Brasil em junho de 2013. Investigam-se as redes sociais como espaço público de ação propícias à construção de uma solidariedade entre cidadãos que agem visando o entendimento. Parte-se do conceito de esfera pública, de Jürgen Habermas, e estende-se a reflexão para o ambiente digital com a abordagem de Yochai Benkler, de esfera pública interconectada, que serve para interpretar o uso das tecnologias de informação e comunicação no cotidiano dos atores sociais a partir da liberação do pólo de emissão de conteúdo.

Palavras-chave: Internet. Redes sociais. Espaço Público. Ação Comunicativa. Esfera Pública.

Abstract: The recent manifestations that took place in Brazil and worldwide inspire the study of various topics and mainly do reflect on the power of action from the use of language. This article verifies the capability of the political use of language on the internet social networks in the light of the concept of political public sphere and with the backdrop of the events that took place in Brazil in June 2013. Social networks are investigated as public space of action conducive to building solidarity between citizens acting in order to establish understanding. It starts from the concept of the public sphere of Jürgen Habermas and It extends the reflection to the digital environment with Yochai Benkler approach of networked public sphere used to interpret the use of technologies of information and communication in everyday due to the release of the production of content.

Keywords: Internet. Social networks. Public Space. Communicative Action. Public Sphere. 


\section{míDiA \\ ecO \\ DiAno}

\section{INTRODUÇÃO}

A investigação da ação política dos movimentos sociais e da opinião pública produzida e incitada pelos atores nas redes sociais digitais é objeto de análise das recentes manifestações ocorridas no país em junho de 2013. A finalidade é refletir sobre o conceito de esfera pública política, adotado por Jürgen Habermas, e pensar as contribuições que o professor Yochai Benkler, da Universidade de Harvard, traz ao afirmar que a mudança da estrutura de esfera pública dominada pela mídia deve ser pensada a partir das relações e das trocas de informações que a rede mundial de computadores propicia.

As redes sociais digitais são o local para o uso político da linguagem, pois nelas organizam-se atos, reivindicam-se ações políticas e mobilizam-se atores da sociedade civil não-politizados, a princípio, mas que se sentem solidários e ativos para manifestar suas insatisfações e esperanças. Como exemplo dessas evidências estão vários movimentos de contestação ao poder estabelecido: Primavera Árabe, Indignados na Espanha, Occupy Wall Street e os protestos de junho de 2013 espalhados por várias capitais do Brasil. O uso das redes sociais digitais como forma de engajar pessoas nesses protestos é o denominador comum como forma de mobilização e tomada de decisão nessa grande teia formada por pessoas com desconfiança das grandes mídias de massa e da classe política no poder.

A partir destas manifestações é preciso pensar o conceito de esfera pública política considerando-se o uso contínuo da internet e, especificamente, das redes sociais digitais pela sociedade civil. As teias e emaranhados de atores tornam essas redes, formadas em princípio no ciberespaço, em verdadeiros espaços públicos virtuais no qual ocorrem mobilizações, deliberações e tomadas de decisão mediados pela linguagem. A conexão entre comunicação livre, mediada por plataformas como Facebook, YouTube e Twitter, e a ocupação do espaço urbano formam, nesse sentido, um espaço público híbrido.

Apesar do acesso às tecnologias de informação e de comunicação ainda não ser universal e da necessidade de uma observação maior no que tange ao engajamento político, conforme Maia (2008, p.285) afirma, “[...] os principais obstáculos para a 


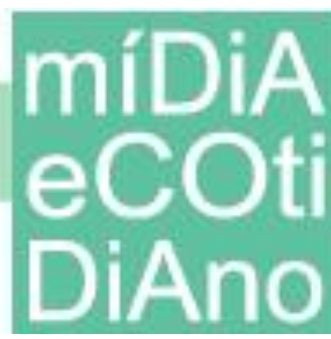

realização da política deliberativa, a qual pressupõe uma resolução discursiva de problemas afetando o interesse comum, advêm geralmente de uma forma de apatia política, e não de empecilhos à liberdade de expressão ou comunicação”.

$\mathrm{Na}$ primeira parte do artigo é feita uma reflexão sobre as redes sociais digitais e o uso das plataformas sociais nas manifestações ocorridas no Brasil fazendo, assim, o curso dessas manifestações e as motivações dos protestos. Em seguida discorre-se sobre as redes sociais digitais como espaço de ação política e, para isso, utiliza-se o argumento de que, mais do que espaço de interação e mobilização, as redes sociais formadas na internet também se configuram como espaços públicos de ação política.

Finaliza-se com uma reflexão sobre o conceito de esfera pública política de Jürgen Habermas $(2003 ;$ 2011) e faz-se uma aproximação entre esse conceito e as redes sociais digitais a partir do argumento de que as pessoas nas redes sociais digitais formam uma nova esfera pública política. Aborda-se o conceito de Benkler (2006), de esfera pública interconectada (tradução livre de networked public sphere) com intuito de atualizar o comportamento dos atores sociais em rede engajados politicamente no ambiente digital.

Por esfera pública interconectada entende-se como definição de uma esfera pública que se aplica na atualidade às mudanças do mundo contemporâneo diante das tecnologias de informação e de comunicação que possibilitam a mediação de debates e a realização de discussões inerentes aos públicos que fazem uso da linguagem para fazer valer o discurso (DINIZ e RIBEIRO, 2012, p. 102).

\section{Redes sociais digitais diante das manifestações no Brasil}

As manifestações ocorridas no Brasil em junho de 2013 não devem ser observadas isoladamente. Diversas outras manifestações ao redor do mundo também são caracterizadas por lutas, que apesar de individualizadas, têm em comum um pano de fundo de contestação ao capitalismo, às políticas neoliberais e a defesa da dignidade humana. 
Em junho de 2013, conforme relata Castells (2013), de forma inesperada e espontânea acontece no Brasil uma grande mobilização de protesto e indignação contra o preço das passagens de ônibus. A reinvindicação se expande para a cobrança por saúde e educação públicas de qualidade, por condições de vida mais dignas e contra a representação política e as ingerências nos recursos públicos explicitadas nos gastos exorbitantes da Copa do Mundo de 2014.

Uma onda de manifestações espalhada pelo país ganha destaque, força e adesão da sociedade civil e é caracterizado como um descontentamento originado, organizado e difundido pelas redes sociais digitais. Como característica peculiar desses eventos, identifica-se por ser livre de uma liderança institucionalizada, ou seja, sem líderes, sem partidos e sindicatos na organização.

Tais manifestações e os devidos desdobramentos passam a ser pauta nas grandes mídias de massa e ganham espaço na opinião pública devido, principalmente, à adesão da sociedade espalhada pelos quatro cantos do Brasil. Uma agitação dessa intensidade não era vista no país desde dois eventos que marcaram a história do país: o impeachment do ex-presidente Fernando Collor de Mello, em 1992, e a campanha Diretas Já realizada na década de 1980.

Apesar do ápice da indignação ter acontecido em junho de 2013, impulsionado, principalmente, pela participação do Movimento Passe Livre, as manifestações populares possuem registro no Brasil, também, em 2003, com o protesto contra o aumento da tarifa do transporte, em Salvador. Este protesto é conhecido como a Revolta do Buzú e se caracteriza por ter sido um movimento no qual as negociações ficaram a cargo de entidades estudantis que decidiram os rumos do movimento a partir da ação direta da população por meio de assembleias horizontais.

A revolta do Buzú é seguida por outro movimento de contestação, mas dessa vez em Florianópolis, no ano de 2004, que fica conhecido como a Revolta da Catraca. Este protesto forçou o poder público a revogar o aumento da passagem na cidade e serviu como base para a fundação do Movimento Passe Livre, em 2005, na plenária do Fórum Mundial, em Porto Alegre. Com isso, o Movimento Passe Livre destaca-se em uma 


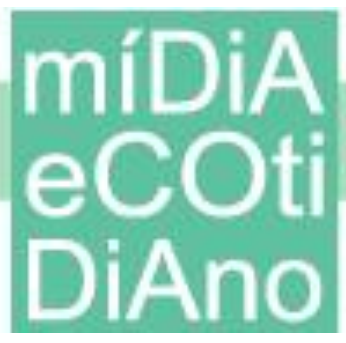

série de manifestações como a ocorrida na cidade de São Paulo, em 2011, que gera grande visibilidade em outras regiões do país.

Em 2012, novo protesto de cerca de duas mil pessoas na cidade de São Paulo ganha grande repercussão, principalmente, em função de uma repressão truculenta por parte da polícia local que tentava evitar a aglomeração de indignados. Em março de 2013 o movimento social é responsável por mais uma manifestação, mas desta vez na cidade de Porto Alegre, no Rio Grande do Sul. As manifestações se espalham em outras cidades do país, como Belém, Brasília, Curitiba, Rio de Janeiro, Salvador e novamente São Paulo.

Em junho de 2013, aproximadamente 150 manifestantes na capital de São Paulo protestam contra o aumento das passagens dos transportes públicos e a favor do passe livre. Esse protesto é debelado pela polícia de forma truculenta por meio de bombas de gás lacrimogêneo e de efeito moral. Diante desse cenário, dá-se início à tática pacífica de enfrentar a polícia sem o uso de violência, por meio do fechamento das avenidas de maior circulação nos horários de rush. As manifestações ganham cobertura da mídia de massa nacional e internacional e gritos de ordem surgem levantados pela massa, como, por exemplo: "o povo acordou", "vem pra rua" e "o gigante acordou".

As pessoas se mobilizam pelos convites feitos nas redes sociais digitais e cidadãos comuns saem às ruas para protestar contra o aumento e o valor das passagens estabelecidos pelos governos locais à época:

Tomando as ruas, as jornadas de junho de 2013 rasgaram toda e qualquer perspectiva técnica acerca das tarifas e da gestão dos transportes que procurasse restringir seu entendimento aos especialistas e sua "racionalidade", a serviço dos de cima. Ao reverter o aumento das passagens em mais de cem cidades do país, as pessoas deslocaram momentaneamente - e com impactos duradouros - o controle político da gestão do transporte. Forjou-se, no calor das barricadas, uma experiência de empoderamento que não se resume à ocupação física das cidades, mas estende-se à maneira como se organizam os transportes no país. É essa tomada de poder que assusta os gestores estatais e privados, que tentam agora reocupar o espaço que perderam para os trabalhadores urbanos (MOVIMENTO PASSE LIVRE, 2013, p.17). 
As manifestações de junho de 2013 evidenciam mais do que um movimento de contestação ao preço da passagem no Brasil. A reação do cidadão de mudar o cenário de indignação se identifica com os problemas de um modelo de crescimento neodesenvolvimentista baseado, exclusivamente, no consumo, o que acarreta, além das dificuldades urbanas, uma crise em todos os domínios da vida, inclusive, no sistema democrático no tocante à representação. Castells (2013) explica as manifestações no país:

Um modelo centrado no crescimento a qualquer custo, ainda que, no caso do Brasil, acompanhado de uma redução da pobreza e de políticas sociais redistributivas. Mas sem assumir a nova cultura da dignidade e do florescimento da vida para além do consumo. Um modelo neodesenvolvimentista, como o chinês e tantos outros, que enveredam por uma senda autodestrutiva com o objetivo de sair da pobreza. Sem entender que a escolarização sem uma verdadeira melhoria do ensino não é educação, mas armazenamento de crianças. E que a saúde sem a potencialização de médicos e enfermeiros e sem um viés preventivo é um poço sem fundo, no qual a produtividade se mede pela ocupação de camas de hospitais, contando os enfermos, e não os sadios (CASTELLS, 2013, p.179).

Citando a dificuldade da população no que abrange a urbanidade e os serviços públicos no Brasil, Rolnik (2013) demonstra a ineficiência de uma política de crescimento voltada apenas para o consumo:

O aumento de renda, que possibilita o crescimento do consumo, não "resolve" nem o problema da falta de urbanidade nem a precariedade dos serviços públicos de educação e saúde, muito menos a inexistência total de sistemas integrados eficientes e acessíveis de transporte ou a enorme fragmentação representada pela dualidade da nossa condição urbana (favela versus asfalto, legal versus ilegal, permanente versus provisório) (ROLNIK, 2013, p.9).

Outra evidência trazida com as manifestações é uma sensação de crise na democracia no que tange à representação política. Fica evidente uma aversão aos 


\section{ecot DiAno}

políticos e aos partidos políticos nos gritos e em faixas e cartazes criados pela população revoltada.

Castells (2013) indaga sobre democracia representativa e poder a seguir:

Como em todo mundo, diziam os manifestantes, a democracia tem sido sequestrada por profissionais da política que, em sua diversidade, estão quase todos de acordo em que a política é coisa de políticos, não dos cidadãos. A democracia foi reduzida a um mercado de votos em eleições realizadas de tempos em tempos, mercado dominado pelo dinheiro, pelo clientelismo e pela manipulação midiática. E essa incapacidade cidadã de controlar seu dinheiro e seus votos tem consequências em todos os âmbitos da vida (CASTELLS, 2013, p.179).

O movimento de junho de 2013 traz ao debate uma série de insatisfações em relação ao transporte público, à cidade como espaço público, à qualidade da educação e da saúde pública. Esse sentimento de indignação ganha amplitude e se difunde nas redes sociais digitais evidenciando a força do agir e da solidariedade nesses espaços virtuais. É fato que cada vez mais a utilização da internet pelas pessoas e das redes sociais digitais, que é formada por diversos atores, amplia para um escopo maior do que o do entretenimento e o da publicidade, pois, continuamente, esse espaço virtual tem sido utilizado para ação política.

\section{Redes sociais digitais como espaço público de ação}

Não é recente o entendimento de que a internet e as redes sociais digitais atuam como um novo espaço público de ação política. Nos laços sociais que se criam forma-se um cenário para expor lutas e reivindicações dos atores que se engajam politicamente. Este espaço é um local ideal de liberdade necessário para uma democracia efetiva. Enfatiza-se o papel fundamental da comunicação na formação e na prática da ação política, pois essas tecnologias continuamente se configuram como um meio poderoso de fortalecer o debate e a interação e, dessa forma, a democracia. 
Configura-se, portanto, nas formas de atuação do que é chamado por Castells (1997) de movimento social da sociedade em rede, pois se origina na crise das organizações institucionalizadas de luta, como os partidos políticos de massa, os sindicatos e as associações cívicas formais. Nestes casos a internet se torna um meio essencial de expressão e organização para as manifestações que se efetivam num espaço público urbano, provocando seu impacto na mídia e, consequentemente, na opinião pública.

Levando em consideração o atual momento, Castells discorre:

Os movimentos sociais do século XXI, ações coletivas deliberadas que visam a transformação de valores e instituições da sociedade, manifestam-se na e pela Internet. [...]. O ciberespaço tornou-se uma ágora eletrônica global em que a diversidade da divergência humana explode numa cacofonia de sotaques (CASTELLS, 2003, p. 114-115).

As manifestações ocorridas no Brasil, que se iniciam contra o aumento nas tarifas de ônibus e, mais especificamente, a manifestação que leva milhares de pessoas às ruas, em São Paulo, no dia 17 de junho de 2013, possui um fator motivador emocional no protesto: a solidariedade na indignação pelos problemas urbanos recorrentes no Brasil e o repúdio à violência sofrida por manifestantes e jornalistas nos protestos ocorridos dias antes.

Com isso, uma massa heterogênea descontente sob um guarda-chuva de pautas e reivindicações é formada, principalmente, a partir do uso das redes sociais digitais: "o chamado feito via redes sociais trouxe as próprias redes sociais para a rua. Quem andou pela Avenida Paulista percebeu que boa parte dos cartazes eram comentários tirados do Facebook e do Twitter" (SAKAMOTO, 2013, p.97).

Nesse sentido, a Internet e as redes sociais digitais reúnem pessoas que são mais do que meros e simples usuários destas plataformas sociais digitais. Assim, estes movimentos ampliam o papel da internet e das redes ao utilizarem essas ferramentas sociais como local de organização, mobilização e deliberação de pautas discutidas em rede. "Sabemos, [...], que a Internet não é simplesmente uma tecnologia: é um meio de 


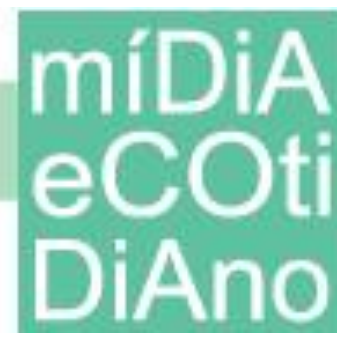

comunicação (como eram as pubs), e é a infra-estrutura material de uma determinada forma organizacional: a rede (como era a fábrica)" (CASTELLS, 2003, p. 116).

Construindo uma comunidade livre num espaço virtual, os movimentos sociais criam um espaço público de deliberação de assuntos diversos, que em última instância, se transforma em um espaço político, no qual assembleias soberanas se realizam e recuperam os direitos de representação, apropriados por instituições políticas ajustadas às conveniências dos interesses e valores dominantes. "O espaço cibernético e o espaço urbano interagem mutuamente e as redes oferecem a oportunidade de pessoas que nunca se movimentaram nesse sentido participarem do processo" (SILVA et al, 2014, p. 145).

Castells destaca, assim, a criação de um espaço híbrido:

Em nossa sociedade, o espaço público dos movimentos sociais é construído como um espaço híbrido entre as redes sociais da internet e o espaço urbano ocupado: conectando o ciberespaço com o espaço urbano numa interação implacável e constituindo, tecnológica e culturalmente, comunidades instantâneas de prática transformadora (CASTELLS, 2013, p.16).

O novo espaço público, o espaço em rede, situado entre os espaços digital e urbano, é um espaço de comunicação autônoma. A autonomia da comunicação é a essência dos movimentos sociais ao permitir que o movimento se forme e possibilite que ele se relacione com a sociedade em geral, pois "quanto mais os sujeitos estão juntos e imersos em um acontecimento de rua, mais intenso e emocional fica o compartilhamento das informações na internet" (MALINI e ANTOUN, 2013, p. 249).

Com isso, a partir do conceito de esfera pública de Jürgen Habermas, esses espaços se configuram como redes de comunicação de conteúdos, tomadas de posição e publicidade das deliberações. Os movimentos publicamente expõem o posicionamento dos cidadãos e, concomitantemente, espalham-se na grande teia e encontram atores engajados em outros movimentos. As características destes novos espaços como nova esfera pública política passam a fazer parte das reflexões a seguir. 


\section{Esfera Pública revisitada: novos modelos na sociedade em rede}

O tema da esfera pública como um espaço no qual os problemas decorrentes da política e do mundo da vida compartilhados entre os atores sociais é discutido ao longo do trabalho de Jürgen Habermas desde o início da carreira acadêmica dele: "[...] a esfera pública, entendida como espaço do trato comunicativo e racional entre as pessoas, é o tema que me persegue a vida toda" (HABERMAS, 2007, p.19).

As funções dessa esfera sofrem modificações no decorrer da teoria de Habermas. O conceito de esfera pública habermasiano aparece em primeiro momento numa dicotomia entre público e privado. A esfera pública se constitui na Europa como o lugar em que a burguesia consumidora de literatura e de arte visitava os cafés e os salões criados apenas para a discussão de temas literários e artísticos. Desses encontros nasce a discussão sobre a ação dos poderes políticos, ou seja, a esfera pública literária surge como modelo de uma esfera pública política.

Entende-se como esfera pública política, na perspectiva de uma teoria da democracia, aquela esfera na qual os atores sociais se organizam e se mobilizam a partir de um problema ou dificuldade comuns e, que por meio da ação política, trazem esses problemas à tona tematizando-os a ponto de sensibilizar o complexo parlamentar.

Habermas confere destaque à esfera pública:

Na perspectiva de uma teoria da democracia, a esfera pública tem que reforçar a pressão exercida pelos problemas, ou seja, ela não pode limitar-se a percebê-los e a identificá-los, devendo, além disso, tematizá-los, problematizá-los e dramatizá-los de modo convincente e eficaz, a ponto de serem assumidos e elaborados pelo complexo parlamentar. E a capacidade de elaboração dos próprios problemas, que é limitada, tem que ser utilizada para um controle ulterior do tratamento dos problemas no âmbito do sistema político (HABERMAS, 2001, p.92). 
A esfera pública pode ser descrita como uma rede adequada para a comunicação de conteúdos, tomadas de posição e opiniões na qual os fluxos comunicacionais se transformam em opiniões públicas que são postas em evidência. A esfera pública se reproduz por meio do agir comunicativo assim como o mundo da vida utiliza a linguagem natural conforme a prática comunicativa cotidiana.

Nesse sentido, para preencher a função de captar e tematizar os problemas da sociedade como um todo, a esfera pública política se forma a partir dos contextos comunicacionais das pessoas virtualmente atingidas. O público que lhe serve de suporte é recrutado no âmbito das pessoas privadas. Somente a esfera da vida privada é capaz de gerar uma linguagem existencial de uma história de vida, que exemplifica os problemas gerados pela sociedade.

Os problemas tematizados na esfera pública política se baseiam na pressão social exercida pelo sofrimento de uma experiência pessoal de vida. Habermas completa a ideia:

A esfera pública pode ser descrita como uma rede adequada para a comunicação de conteúdos, tomadas de posição e opiniões; nela os fluxos comunicacionais são filtrados e sintetizados, a ponto de se condensarem em opiniões públicas enfeixadas em temas específicos. Do mesmo modo que o mundo da vida tomado globalmente, a esfera pública se reproduz através do agir comunicativo, implicando apenas o domínio de uma linguagem natural; ela está em sintonia com a compreensibilidade geral da prática comunicativa cotidiana (HABERMAS, 2011, p.93).

A esfera pública, entretanto, não assume para si inteiramente as funções politicamente relevantes e também não se manifesta diretamente em uma contribuição política, mas reforça a pressão no sistema político, deixando a cargo do complexo parlamentar a elaboração especializada. Habermas completa:

Todavia, a esfera pública não se especializa em nenhuma destas direções; por isso quando abrange questões politicamente relevantes, ela deixa ao cargo do sistema político a elaboração especializada. A esfera pública constitui principalmente uma estrutura comunicacional do agir orientado pelo entendimento, a qual tem a ver com o espaço social 
erado no agir comunicativo, não com as funções nem com os conteúdos da comunicação cotidiana (HABERMAS, 2011, p.93).

Não é mais possível delimitar o espaço da esfera pública apenas nos tempos em que essa esfera se encontrava nos bares e cafés literários. O local da atual esfera pública deve considerar o que se reconhece como agir comunicativo na esfera pública. Habermas complementa a ideia:

A esfera pública se diferencia por níveis, de acordo com a densidade da comunicação, da complexidade organizacional e do alcance, formando três tipos de esfera pública: esfera pública episódica (bares, cafés, encontros na rua), esfera pública da presença organizada (encontros de pais, público que frequenta o teatro, concertos de Rock, reuniões de partidos ou congressos de igrejas) e esfera pública abstrata, produzida pela mídia (leitores, ouvintes e espectadores singulares e espalhados globalmente) (HABERMAS, 2011, p.96).

Nesse sentido, Habermas dá destaque ao uso da linguagem

Qualquer encontro que não se limita a contatos de observação mútua, mas que se alimenta da liberdade comunicativa que uns concedem aos outros, movimenta-se num espaço público, constituído através da linguagem. Em princípio, ele está aberto para parceiros potenciais do diálogo, que se encontram presentes ou que poderiam vir a se juntar (HABERMAS, 2011, p.93).

As manifestações ocorridas no Brasil demonstram que os encontros e as mobilizações que se configuram a partir do agir comunicativo têm como espaço de ação principalmente a internet e as redes sociais digitais. Apesar de Habermas privilegiar na teoria dele os espaços concretos de um público presente e indicar os perigos de substituição das interações simples para a generalização da presença virtual de leitores situados em lugares distantes, ocasionados pelo uso da mídia, cada vez mais a internet rompe essa distância e as interações que necessitavam de um espaço concreto continuamente são realizadas por meio virtual. 
Habermas aponta para uma generalização da esfera pública:

[...] as esferas públicas ainda estão muito ligadas aos espaços concretos de um público presente. Quanto mais elas se desligam de sua presença física, integrando também, por exemplo, a presença virtual de leitores situados em lugares distantes, de ouvintes ou espectadores, o que é possível através da mídia, tanto mais clara se torna a abstração que acompanha a passagem da estrutura espacial das interações simples para a generalização da esfera pública (HABERMAS, 2011, p.94).

Sendo assim, as mobilizações e tomadas de decisões que formaram as manifestações ocorridas no Brasil e no mundo, apesar de se realizem nos espaços públicos urbanos concretos também se efetivaram no ambiente virtual da internet e por meio da mediação das redes sociais. Com isso, atenta-se para a necessidade de ampliação do conceito de esfera pública para esses novos espaços de interação e de comunicação.

Com esse objetivo, traz-se o conceito de esfera pública interconectada, de Yochai Benkler (2006), que tendo como perspectiva a relação entre redes sociais digitais e liberdade, a diferença fundamental entre a esfera pública dominada pela mídia e a esfera pública interconectada se dá pela arquitetura da rede e pela eliminação de custos por parte do emissor.

\section{Esfera Pública interconectada como Esfera Pública Política}

Benkler (2006, p. 400), conforme apontam Lima et al (2012), afirma que "a produção colaborativa emerge como sistema técnico social, viável, para motivar e organizar as contribuições coletivas humanas por outros meios que não sejam os contratos e a compensação do mercado". A produção colaborativa é a realização de uma atividade voltada para o comum e as redes de produção colaborativa da sociedade atual têm características participativas e horizontais, entre produtores e usuários, que são diferentes das relações entre produtores, mediadores e consumidores do modo de desenvolvimento industrial do capitalismo. 
A percepção do mundo não deve mais ser aceita como mera observação privada, mas como assunto potencial da comunicação pública. Essa mudança afeta o poder relativo da mídia, a estrutura de absorção de observações e pontos de vista, a apresentação de questões e de observações no discurso e o jeito que as questões são filtradas para quem e por quem. As maneiras como as posições são cristalizadas e sintetizadas, algumas vezes, com essas sendo ampliadas ao ponto da mídia de massa passar a considerá-las e convertê-las em posições políticas, também são afetadas, mas, ocasionalmente, nesse caso, por meio da organização direta da opinião e da ação, ao ponto delas alcançarem uma relevância capaz de dirigir o processo político diretamente (BENKLER, 2006, p. 213, tradução nossa).

Destaca-se que a esfera pública interconectada não é feita de ferramentas, mas das práticas de produção social que essas ferramentas possibilitam. O efeito primário da internet na esfera pública em sociedades liberais recai na produção informacional de atores de fora do mercado: o trabalho de indivíduos sozinhos e em cooperação com outros, ou de associações formais como organizações não-governamentais (ONGs), bem como o retorno do seu efeito sobre a mídia tradicional (BENKLER, 2006, p. 219, tradução nossa).

$\mathrm{Na}$ esfera pública interconectada é possível moderar as duas maiores preocupações motivadas pela mídia de massa comercial como uma plataforma para a esfera pública: (1) o excessivo poder que ela dá aos seus proprietários e (2) a sua tendência, quando os proprietários não dedicam os seus meios a concentrar poder ou de encorajar uma política inerte. Fundamentalmente as práticas sociais da informação e do discurso possibilitam que um grande número de atores se veja como contribuidores potenciais para o discurso público diante de uma arena política deixando de serem receptores passivos da informação mediada (BENKLER, 2006, p. 219, tradução nossa).

Os novos meios de comunicação baseados na rede podem exercer uma força contrária significativa. Eles oferecem uma base de absorção completamente nova e muito mais aberta para ideias, interações e comentários. A velocidade com que indivíduos são capazes de publicar sites para ocupar uma posição, coletar e tornar disponíveis informações relevantes para um assunto específico de interesse público, e 


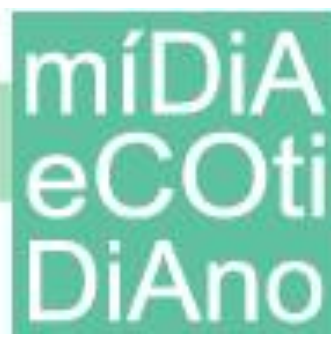

prover uma plataforma para outros compartilharem suas visões sobre estratégias políticas apropriadas e suas táticas são completamente diferentes de qualquer coisa factível dentro da estrutura econômica e organizacional da mídia de massa (BENKLER, 2006, p. 225, tradução nossa).

A batalha pela ecologia institucional do ambiente digital, como afirma Benkler (2006, p. 383) é complexa para a prática social. Para o autor, estamos no meio de uma transformação bastante básica da maneira como percebemos o mundo a nossa volta, e como agimos, isoladamente, e em conjunto com outros, de forma a moldar a nossa própria compreensão do mundo que ocupamos e dos outros com quem o compartilhamos (BENKLER, 2006, p. 472, tradução nossa). Da esfera pública interconectada, portanto, espera-se que decisões políticas envolvam mais a participação de indivíduos que, em rede, conectam-se e ampliam discursivamente os debates por meio da linguagem.

O conteúdo produzido e compartilhado sem custos por um misto de usuários híbridos (produtores e consumidores de informação e de conhecimento) derruba o paradigma existente de antes do surgimento de uma sociedade em que os contatos passam a ser mediados por tecnologia digital. A comunicação de muitos para muitos amplia a produção de conhecimento e coloca a sociedade civil global em destaque com capacidade de ser ouvida por meio do discurso que se estabelece nesses meios (GONÇALVES e LIMA, 2014). É preciso, nesse sentido, estar atento aos atores envolvidos nos processos de participação em que a linguagem motiva novos discursos.

\section{CONCLUSÃO}

O presente artigo discorre sobre a relação entre espaço público de ação política, especificamente a internet com suas redes sociais digitais, e o conceito de esfera pública de Jürgen Habermas, tendo como ponto de partida para as reflexões as manifestações ocorridas no Brasil, em junho de 2013. Essas manifestações, que se espalharam pelo Brasil como inicialmente uma reivindicação única relacionada ao fim do aumento da passagem, se estenderam de tal maneira que os objetivos iniciais se transformaram em 


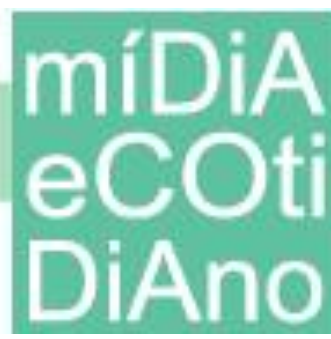

um grito de indignação coletivo pela cobrança por melhor educação e saúde pública de qualidade, pelo fim da corrupção e por outras reivindicações.

A abertura desse leque de reivindicações é possível justamente pela participação de atores sociais que vislumbram uma oportunidade de atuar em uma arena política discursiva levantando insatisfações por meio da atuação coletiva mediada pelas redes sociais digitais. Esses atores, em grande parte, são mobilizados por meio das conexões que os mesmos fazem na rede mundial de computadores, pois reconhece-se que a internet e as redes sociais digitais já se configuram como espaços de ação política que permitem discussões e, possivelmente, tomadas de decisões.

Apesar dos espaços virtuais serem cada vez mais utilizados como espaços públicos de ação política, o conceito de esfera pública política de Habermas ainda não reconhece esses espaços como locais de agir. Sendo assim, atenta-se para a necessidade de ampliação do conceito de esfera pública para esses novos espaços digitais de interação e de comunicação. Uma possibilidade de ampliação, portanto, é o conceito de esfera pública interconectada de Yochai Benkler.

\section{REFERENCIAS}

BENKLER, Yochai. The wealth of networks: how social production transforms markets and freedom. USA: Yale University Press, 2006.

CASTELLS, Manuel. A galáxia da Internet: reflexões sobre a internet, os negócios e a sociedade. Rio de Janeiro: Zahar, 2003.

Redes de indignação e esperança: movimentos sociais na era da internet. Rio de Janeiro: Zahar, 2013.

A sociedade em rede. v.1. São Paulo: Paz e terra, 2011.

DINIZ, Eduardo H.; RIBEIRO, Manuella Maia. O conceito de esfera pública interconectada e o site "webcidadania" no Brasil. Gestão \& Regionalidade. V. 28, n. 83., mai-ago, 2012.

FERNANDES, Edson; ROSENO, Ricardo de Freitas. Protesta Brasil: das redes sociais às manifestações de rua. São Paulo. Prata editora, 2013. 


\section{míDiA

GONÇALVES, Marcio; LIMA, Clóvis R. M. de. Validação discursiva da informação na Wikipédia. Saarbrücken: Novas Edições Acadêmicas, 2014.

HABERMAS, Jurgen. Direito e Democracia: entre facticidade e validade. v.2. Rio de Janeiro: Tempo Brasileiro, 2011.

Entre naturalismo e religião: estudos filosóficos. Rio de Janeiro: Tempo Brasileiro, 2007.

2007.

A inclusão do outro: estudos de teoria política. São Paulo: Edições Loyola,

Mudança estrutural da esfera pública: investigações quanto a uma categoria da sociedade burguesa. 2. ed. Rio de Janeiro: Tempo Brasileiro, 2003.

Sobre a constituição da Europa: um ensaio. São Paulo: UNESP, 2013.

LIMA, Clóvis; GONÇALVES, M.; MEIRELlES, M.; CASTRO, B. L. de. Os ambientes wiki: interação, discurso e generosidade nas redes sociais. In: Encontro Nacional de Pesquisa em Ciência da Informação, 13, 2012, Rio de Janeiro. Anais, Rio de Janeiro, 2012.

MALINI, Fábio; ANTOUN, Henrique. A internet e a rua: ciberativismo e mobilização nas redes sociais. Porto Alegre: Sulina, 2013.

Movimento Passe Livre. Não começou em Salvador, não vai terminar em São Paulo. In: CIDADES rebeldes: passe livre e as manifestações que tomaram as ruas do Brasil. São Paulo: Boitempo; Carta Maior, 2013.

ROLNIK, Raquel. As vozes das ruas: as revoltas de junho e suas interpretações. In: CIDADES rebeldes: passe livre e as manifestações que tomaram as ruas do Brasil. São Paulo: Boitempo; Carta Maior, 2013.

SAKAMOTO, Leonardo. Em São Paulo, o Facebook e o Twitter foram às ruas. In: CIDADES rebeldes: passe livre e as manifestações que tomaram as ruas do Brasil. São Paulo: Boitempo; Carta Maior, 2013.

SILVA, Regina H. Alves da; GUEDES, Inês C; JURNO, Amanda C.;PAULA, Gabriel M. R de. Vandalismo e política nas redes sociais: caso do Anonymous e Black Bloc. In: SILVA, Regina Helena Alves da (Org.) Ruas e redes: dinâmicas dos protestosBR. Belo Horizonte: Autêntica Editora, 2014. 